\title{
Detección de la falla de transferencia pasiva en potrillos mediante dos pruebas serológicas rápidas
}

\author{
Palomino, J.A. \\ Facultad de Medicina Veterinaria, Universidad Alas Peruanas, \\ Pachacamac, Perú. E-mail: mv.joe19607@gmail.com
}

\begin{abstract}
Resumen
Palomino, J.A.: Detección de la falla de transferencia pasiva en potrillos mediante dos pruebas serológicas rápidas. Rev. vet. 32: 1, 120-126, 2021. El propósito de este estudio fue detectar la falla de la transferencia pasiva (FTP) en potrillos de un hospital veterinario del Perú, usando las pruebas de coagulación por glutaraldehído y la medición de la concentración de las proteínas séricas totales por refractometría, y evaluar la concordancia entre ambas pruebas. Treinta y un potrillos con 24 horas de vida fueron seleccionados para este estudio. De cada potrillo se extrajo $3 \mathrm{ml}$ de sangre por venopunción yugular, de donde se obtuvo 1 a $1,5 \mathrm{ml}$ de suero. Para la prueba de coagulación por glutaraldehído se utilizó $0,5 \mathrm{ml}$ de suero sanguíneo y una gota de glutaraldehído al $10 \%$, y para la prueba de refractometría fueron necesarias 2 gotas del suero sanguíneo. De los 31 potrillos evaluados, $8(25,81 \%)$ y $9(29,03 \%)$ potrillos fueron detectados con la FTP mediante las pruebas de coagulación por glutaraldehído y refractometría, respectivamente. Por lo tanto, el índice kappa fue de 0.93 . Ambas pruebas pueden ser usadas para el diagnóstico de FTP dada su sencillez, bajo costo y resultados inmediatos.
\end{abstract}

Palabras clave: glutaraldehído, proteínas séricas totales, refractometría.

\begin{abstract}
Palomino, J.A.: Detection of failure of passive transference in foals using two rapid serological tests. Rev. vet. 32: 1, 120-126, 2021. The purpose of this study was to detect the failure of passive transfer (FTP) in foals of a veterinary hospital of Peru, using the glutaraldehyde coagulation test and the measurement of total serum protein concentration by refractometry, and to evaluate the concordance between both tests. Thirty-one foals with 24 hours of age were selected for this study. From each foal, $3 \mathrm{ml}$ of blood was extracted by jugular venipuncture, from which 1 to $1.5 \mathrm{ml}$ serum was obtained. For the glutaraldehyde coagulation test, 0.5 $\mathrm{ml}$ of blood serum and one drop of $10 \%$ glutaraldehyde were used, and for the refractometry test, 2 drops of blood serum were necessary. Of 31 foals evaluated, 8 (25.81\%) and $9(29.03 \%)$ foals were detected with FPT using the glutaraldehyde coagulation test and refractometry, respectively. Therefore, the kappa index was 0.93 . Both tests can be used to diagnose FPT because they are simple, cheap and with immediate results.
\end{abstract}

Key words: glutaraldehyde, total serum proteins, refractometry.

\section{INTRODUCCIÓN}

La falla de la transferencia pasiva (FTP) de los anticuerpos maternos, específicamente la inmunoglobulina G (IgG), ocurre cuando no hay una correcta absorción del calostro dentro de las primeras 24 horas de vida del potrillo recién nacido y aumenta el riesgo de contraer alguna enfermedad infecciosa ${ }^{1-3}$. La FTP también puede ocurrir cuando la yegua no puede producir calostro en volúmenes adecuados, o bien una cantidad pobre de anticuerpos calostrales, o la incapacidad del potro para ingerir calostro, o cuando la yegua rechaza el potro ${ }^{3}$.

La incidencia de FTP se ha reportado entre el 3 y $30 \%$ en potros de pura sangre o ecuestres de salto, sin diferencias significativas entre el número de embarazos, la edad de la yegua, o el sexo del potro ${ }^{4-6}$. La única diferencia observable sobre los distintos porcentajes de incidencias se debe a los países donde fueron desarrollados.

Existen pruebas cuantitativas y cualitativas para la evaluación del estado inmunológico del potrillo. Las pruebas cuantitativas son más precisas, difíciles de realizar en el campo y requieren mucho tiempo para leer los resultados ${ }^{7}$. Mientras tanto, las pruebas cualitativas proporcionan resultados más rápidos y son más fáciles de realizar en el campo porque no requieren de muchos materiales ${ }^{6,8,9}$.

La prueba de coagulación por glutaraldehído es uno de los estudios cualitativos más utilizados, e incluso existen kits comerciales que han probado tener buenos resultados diagnósticos ${ }^{9}$. Otra prueba cualita- 
tiva es la refractometría, usada para evaluar el calostro, aunque también es útil para medir las proteínas séricas totales (PST) ${ }^{1}$. Como las globulinas son las proteínas con la concentración más alta en el suero sanguíneo, las proteínas séricas y las globulinas mantienen una relación indirecta ${ }^{5-7}$.

El objetivo del presente estudio fue detectar la falla de la transferencia pasiva en potrillos de un hospital veterinario, utilizando la prueba de coagulación por glutaraldehído y la refractometría, así como evaluar la correlación entre ambas pruebas.

\section{MATERIAL Y MÉTODOS}

Treinta y un potrillos de yeguas Zangersheide del Hospital Veterinario Central del Ejército del Perú, fueron evaluados en el estudio. Se obtuvieron $3 \mathrm{ml} \mathrm{de}$ sangre mediante venopunción yugular de cada potro a las 24 horas después del parto ${ }^{4,6}$. Los tubos con las muestras de sangre se colocaron a baño maría (30$35^{\circ} \mathrm{C}$ ) durante 30 minutos, para lograr separar el suero de la sangre. De cada potrillo se obtuvo entre 1 a 1,5 $\mathrm{ml}$ de suero sanguíneo, que fueron separados en tubos nuevos y procesados inmediatamente.

Para la prueba de coagulación con glutaraldehído se usó $0,5 \mathrm{ml}$ de suero y una gota de glutaraldehído al $10 \%$, el cual formó un coágulo en el fondo del tubo ${ }^{9,10}$. El tiempo de la formación del coágulo fue medido con un cronómetro estándar.

La cantidad de tiempo que tardó en formar el coágulo indicó la concentración de inmunoglobulinas presentes en el suero. Si el tiempo fue menor a 10 minutos indicó que el potrillo tenía una alta concentración de IgG $(\geq 800 \mathrm{mg} / \mathrm{dl})$. Por otro lado, si tardaba más de 10 minutos se confirmaba la existencia de una falla de la transferencia pasiva ${ }^{9}$.

Para la refractometría se colocó una gota de suero sanguíneo en el prisma del refractómetro (refractómetro manual ATC de 3 escalas, para uso clínico veterinario). Los valores óptimos de las PST son $\geq 6 \mathrm{~g} / \mathrm{dl}$ y cuando se encuentran por debajo de esta cantidad se considera una falla de la transferencia pasiva ${ }^{9}$.

Algunos autores mencionan una falla parcial de la transferencia pasiva, pero tal característica no fue incluida en este estudio por tratarse de pruebas cualitativas y no tener una prueba cuantitativa como la inmuno-difusión radial (RID) que respalde estas diferencias $^{2,4,6}$.

El índice kappa fue el método estadístico utilizado para determinar la concordancia entre las pruebas de coagulación por glutaraldehído y refractometría.

\section{RESULTADOS Y DISCUSIÓN}

Los resultados de la FTP en los 31 potrillos evaluados mediante las pruebas de coagulación con glutaraldehído y refractometría fueron de $8(25,81 \%)$ y 9 $(29,03 \%)$ potrillos, respectivamente. El índice kappa para estas dos pruebas fue de 0,925 , interpretándose como una concordancia muy buena o casi perfecta.

A pesar de que el tamaño de muestra fue menor en comparación a otros estudios, los animales muestreados en esta investigación representaron la población total de potrillos en el hospital citado. Por tal motivo, el porcentaje de potrillos con FTP $(25,81$ y $29,03 \%$ según las pruebas de coagulación por glutaraldehído y refractometría, respectivamente) resulta ser alarmante por encontrarse en el límite superior a lo reportado (3$30 \%)^{4,5,7}$

Aunque la RID es la prueba gold standard para la detección de FTP, tarda 24 horas para obtener los resultados, lo cual resulta contraproducente al momento de realizar un tratamiento correctivo ${ }^{6,7,9}$. Por tal motivo, el uso de pruebas rápidas como la refractometría para la medición de las PST resulta útil para dar un tratamiento temprano y reducir el riesgo a una infección ${ }^{6}$.

La refractometría -al igual que la calostrometríaes usualmente usada para la evaluación del calostro ${ }^{1 \text {, }}$ 7 . A pesar de ello, su importancia como método diagnóstico para la FTP está aumentando, tanto como su aceptación ${ }^{1,5,6,11}$. Otros investigadores ${ }^{5,8}$ evaluaron la correlación entre las pruebas de refractometría y el kit de RID, obteniendo un valor promedio de 0,80 , lo cual indica una concordancia considerable. En tal sentido, los resultados obtenidos en este estudio llegan a ser tan confiables como una prueba cuantitativa, aunque ello no descarta su importancia para realizar evaluaciones más precisas.

El uso de la prueba de coagulación con glutaraldehído y la refractometría son bien aceptadas para trabajos en campo, debido que son pruebas sencillas, de bajo costo y que brindan resultados rápidos ${ }^{8}$. De esta manera, todos los potrillos positivos a la FTP pudieron ser tratados a tiempo, aunque lamentablemente fallecieron 2 de ellos por complicaciones en su salud.

Agradecimientos. Al Comandante General Curo Maquén y al Comandante Juan Bravo por permitirme realizar esta investigación en el Hospital Veterinario Central del Ejército del Perú.

\section{REFERENCIAS}

1. Auad J, Lozano A, Cooper L, Cerutti J, Davalos M, Mangeaud A. 2010. Fisiología de la transferencia pasiva de anticuerpos en equinos, Ed. FAVE, Sección Ciencias Veterinarias 9: 69-75.

2. Barton MH, Hart KA. 2020. Clinical pathology in the foal. Vet Clin North Am Equine Pract 36: 73-85.

3. Carabetta D, Fernández D, Etcheverría A, Valle $M$, Padola NL. 2016. Evaluación de la transferencia pasiva de la inmunidad en equinos mediante el uso de diferentes pruebas. InVet 18: 333-340.

4. Deelen SM, Ollivett TL, Haines DM, Leslie KE. 2014. Evaluation of a Brix refractometer to estimate serum immunoglobulin $\mathrm{G}$ concentration in neonatal dairy calves. $J$ Dairy Sci 97: 3838-3844. 
5. Fouché N, GraubnerC, Howard J. 2014. Correlation between serum total globulins and gamma globulins and their use to diagnose failure of passive transfer in foals. Vet J 202: 384-386.

6. Francesca F, Jole M, Aliai L, Chiara C, Carolina C. 2017. Efficacy and safety of a commercial fresh-frozen hyperimmune plasma in foals with failure of passive transfer of immunity. J Equine Vet Sci 48: 174-181.

7. Kenzig AR, O'Meara KM, Kremer CJ, Jogan KS, Jack NE, Cole K. 2009. Colostral, milk and serum immunoglobulin $\mathrm{G}$ concentrations in quarter horse mares and their foals. JEquine Vet Sci 29: 486-487.

8. Korosue K, Murase H, Sato F, Ishimaru M, Kotoyori Y, Nambo Y. 2012. Correlation of serum IgG concentration in foals and refractometry index of the dam's pre- and post-parturient colostrums: an assessment for failure of passive transfer in foals. J Vet Med Sci 74: 1387-1395.
9. McCracken MM, Morrill KM, Fordyce AL, Tyler HD. 2017. Technical note: evaluation of digital refractometers to estimate serum immunoglobulin $\mathrm{G}$ concentration and passive transfer in Jersey calves. J Dairy Sci 100: 84388442 .

10. Weaver DM, Tyler JW, VanMetre DC, Hostetler DE, Barrington GM. 2000. Passive transfer of colostral immunoglobulins in calves. J Vet Intern Med 14: 569-577.

11. Yalcin E, Temizel EM, Yalcin A, Carkungoz E. 2010. Relationship with gamma glutamyl transferase activity and glutaraldehyde coagulation test of serum immunoglobulin G concentration in newborn goat kids. Small Rumin Res 93: 61-63. 